\title{
Right ventricle-to-pulmonary artery conduits: Do we really have an option?
}

\author{
Bahaaldin Alsoufi, MD
}

\footnotetext{
From the Division of Cardiothoracic Surgery, Emory University School of Medicine, Children's Healthcare of Atlanta, Atlanta, Ga.

Disclosures: Author has nothing to disclose with regard to commercial support.

Received for publication Oct 25, 2015; accepted for publication Oct 26, 2015; available ahead of print Nov 19, 2015.

Address for reprints: Bahaaldin Alsoufi, MD, Division of Cardiothoracic Surgery, Emory University School of Medicine, Children's Healthcare of Atlanta, 1405 Clifton Rd NE, Atlanta, GA 30322 (E-mail: balsoufi@ hotmail.com).

J Thorac Cardiovasc Surg 2016;151:442-3

$0022-5223 / \$ 36.00$

Copyright (c) 2016 by The American Association for Thoracic Surgery

http://dx.doi.org/10.1016/j.jtcvs.2015.10.100
}

Reconstruction of right ventricle-to-pulmonary artery (RVPA) continuity is an integral part of various surgical procedures commonly performed in neonates and young infants to repair congenital cardiac defects. Despite our initial success in treating those complex patients, this part of the repair seems to be the "gift that keeps on giving," and RV-PA reinterventions, both surgical and catheter based, have rapidly become among the most common procedures performed in children, let alone adults, with congenital heart disease.

The question of the ideal RV-PA conduit has been extensively investigated, and needless to say a perfect RV-PA conduit does not exist. Several factors that influence RV-PA conduit reintervention risk have been identified, these include the patient's age and weight, the underlying anatomy, the quality of the branch pulmonary arteries, and of course conduit type and size. ${ }^{1-4}$ In this issue of The Journal of Thoracic and Cardiovascular Surgery, Mery and colleagues ${ }^{5}$ from Houston have reported another large single-institution experience with 792 RV-PA conduits placed through the course of 20 years. They examined factors associated with conduit reintervention and replacement, with a focus on the incidence and risk factors for endocarditis. With regard to conduit longevity, their findings were not surprising; again age, conduit size, and anatomy were associated with more reinterventions. In addition, similar to other reports, ${ }^{6}$ they found that the bovine jugular grafts (Contegra Pulmonary Valved Conduit, Medtronic Inc, Minneapolis, Minn), were associated with longer durability and lower reintervention risk.

One of the more interesting findings in that study is that the risk of endocarditis was remarkably higher in children who received bovine jugular grafts, with a 9-fold hazard increase and $83 \%$ freedom from endocarditis at 10 years after implantation, versus $95 \%$ to $100 \%$ freedom for the other conduit choices. Again, this finding is not novel, as several series have previously reported the higher occurrence of colleagues. $^{5}$

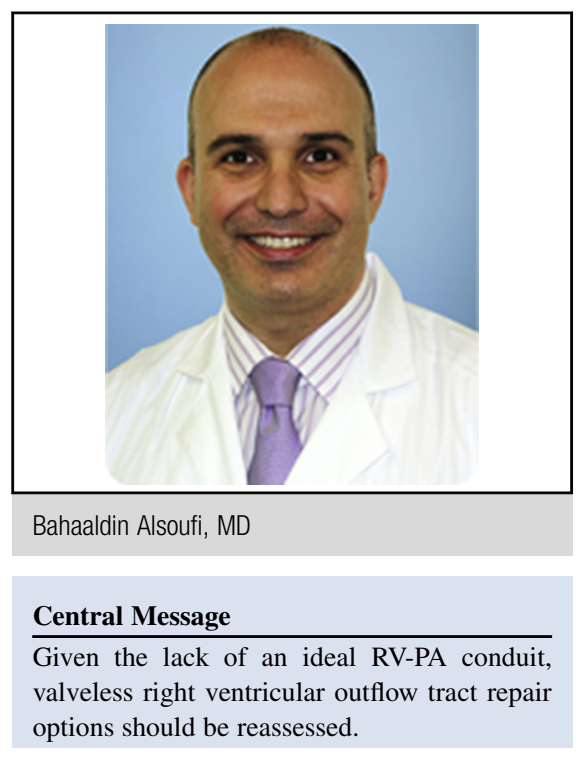

See Article page 432.

endocarditis for jugular vein grafts. ${ }^{7,8}$ Nonetheless, the incidence of this complication in the report of Mery and colleagues $^{5}$ seems to be more elevated and therefore more alarming. This finding might be partly related to the longer durability of those conduits, making them the victims of their own success by keeping them exposed to the infection risk for a longer time. Nonetheless, it is doubtful that this hypothesis can account completely for the significant increased endocarditis risk, and a complete mechanical explanation of this higher risk remains elusive. Several factors likely play a role, including inherent tissue characteristics that increase the conduit susceptibility to infection, the risk of thrombus formation especially in patients with distal obstruction, the mode of valve degeneration, and the subsequent disturbances of flow. It is also plausible that associated patient-related factors play a role. The jugular vein grafts are more commonly placed in smaller children, who typically are more likely to require delayed sternal closure, longer hospitalization, and longer duration of invasive lines. Additionally, those small children more commonly have distal hypoplasia or stenosis in the pulmonary artery tree, with associated flow turbulences and a more frequent need for invasive imaging and interventions. All these factors can expose the children to increased contamination and subsequent infection risk that can be acute or latent, as shown in the report of Mery and 
Consequently, Mery and colleagues ${ }^{5}$ have become more cautious when selecting the RV-PA conduit and have decreased their use of jugular vein grafts in favor of other valve choices. Their report is certainly provocative and stimulates others to follow suit. The problem is that the surgeon is at the mercy of available choices, and the question remains: Do we really have an option? On the basis of what we know now, we need to choose a conduit taking into consideration the risks of stenosis, regurgitation, and endocarditis. In larger children, this selection task is easier, because it appears that tissue prostheses that can be sutured to the right ventricular outflow tract or incorporated into a Dacron polyester fabric conduit are associated with longer durability, lower incidence of compression-associated regurgitation, and low risk of endocarditis. ${ }^{1}$ The use of bovine jugular grafts or even homografts in this group of patients is therefore likely avoidable and possibly advisable. On the other hand, the selection task for neonates and small infants is more challenging. Tissue prostheses are too large to implant, and small-sized homografts are not always available. In addition, conduit stenosis and regurgitation risks are the highest in this group of patients as a result of rapid degeneration, anastomotic stricture, external compression, geometric disruption related to size mismatch, and finally distal pulmonary artery obstruction. ${ }^{1-5}$ The bovine jugular grafts have gained popularity among surgeons in this patient population because of their availability, ease of implantation, reasonable competency, and durability. Despite the endocarditis risk, it would be difficult to avoid completely the use of those conduits in neonates and small infants. One possibility is the elimination of the use of RV-PA conduit for right ventricular outflow tract reconstruction during the initial repair in favor of valveless repair. This has been described for the repair of several lesions, such as truncus arteriosus, pulmonary atresia with ventricular septal defect, tetralogy of Fallot with absent pulmonary valve, and dextrotransposition of the great arteries with ventricular defect and pulmonary stenosis. Although freedoms from reoperation in those patients who have received valveless reconstruction of RV-PA continuity have repeatedly been shown to be superior, many surgeons have still been hesitant to adopt those repair strategies because of the risk of free pulmonary regurgitation, especially in patients with pulmonary hypertension or diastolic right ventricular dysfunction, which can be associated with a more protracted postoperative recovery and high inhospital mortality. Additional concerns are related to the effects of persistent pulmonary regurgitation on progressive enlargement of the right ventricle and subsequent tricuspid valve dysfunction and to arrhythmia complications affecting long-term survival and functional status. Nonetheless, given the current advances in perioperative care and management of pulmonary hypertension and ventricular dysfunction, those repair strategies might need to be reconsidered, especially because many of the conduits in those small neonates are not actually competent early on. The detrimental effects of chronic pulmonary regurgitation on the late function of the right ventricle and tricuspid valve can be mitigated with timely surgical or percutaneous implantation of a tissue prosthesis.

Despite all the triumphs, surgical repair of congenital heart defects is rarely corrective, and reinterventions are the norm rather than the exception for many cardiac defects. The surgeons are always on the mission to use available knowledge and tools at their disposal to improve outcomes of their patients, and that can be in the form of minimizing late morbidity including cardiac reoperations and improving quality of life. It might be the time to reassess our strategies for right ventricular outflow tract reconstruction.

\section{References}

1. Dearani JA, Danielson GK, Puga FJ, Schaff HV, Warnes CW, Driscoll DJ, et al Late follow-up of 1095 patients undergoing operation for complex congenital heart disease utilizing pulmonary ventricle to pulmonary artery conduits. Ann Thorac Surg. 2003;75:399-410; discussion 410-1.

2. Karamlou T, Blackstone EH, Hawkins JA, Jacobs ML, Kanter KR, Brown JW et al. Pulmonary Conduit Working Group for the members of the Congenital Heart Surgeons Society. Can pulmonary conduit dysfunction and failure be reduced in infants and children less than age 2 years at initial implantation? J Thorac Cardiovasc Surg. 2006;132:829-38.

3. Caldarone CA, McCrindle BW, Van Arsdell GS, Coles JG, Webb G, Freedom RM et al. Independent factors associated with longevity of prosthetic pulmonary valves and valved conduits. J Thorac Cardiovasc Surg. 2000;120:1022-30; discussion 1031.

4. Poynter JA, Eghtesady P, McCrindle BW, Walters HL III, Kirshbom PM Blackstone EH, et al. Congenital Heart Surgeons' Society. Association of pulmonary conduit type and size with durability in infants and young children. Ann Thorac Surg. 2013;96:1695-701; discussion 1701-2.

5. Mery CM, Guzmán-Pruneda FA, De León LE, Zhang W, Terwelp MD, Bocchini CE, et al. Risk factors for development of endocarditis and reintervention 1 in patients undergoing right ventricle to pulmonary artery valved conduit placement. J Thorac Cardiovasc Surg. 2016;151:432-41.

6. Hickey EJ, McCrindle BW, Blackstone EH, Yeh T Jr, Pigula F, Clarke D, et al CHSS Pulmonary Conduit Working Group. Jugular venous valved conduit (Contegra) matches allograft performance in infant truncus arteriosus repair. Eur J Cardiothorac Surg. 2008;33:890-8.

7. Ugaki S, Rutledge J, Al Aklabi M, Ross DB, Adatia I, Rebeyka IM. An increased incidence of conduit endocarditis in patients receiving bovine jugular vein grafts compared to cryopreserved homograft for right ventricular outflow reconstruction. Ann Thorac Surg. 2015;99:140-6.

8. Albanesi F, Sekarski N, Lambrou D, Von Segesser LK, Berdajs DA. Incidence and risk factors for Contegra graft infection following right ventricular outflow tract reconstruction: long-term results. Eur J Cardiothorac Surg. 2014;45:1070-4. 